\title{
NOTES
}

\section{Preparation of Organic/Inorganic Polymer Hybrid from a New Class of Novolac}

\author{
Tsuyoshi KimURA, Yoshiaki NAKAmoto, and Gen-ichi Konishi ${ }^{\dagger, \dagger \dagger}$ \\ Division of Material Engineering, Graduate School of Natural Science \& Technology, \\ Kanazawa University, Kakuma-machi, Kanazawa 920-1192, Japan
}

(Received January 26, 2006; Accepted February 17, 2006; Published May 25, 2006)

\begin{abstract}
KEY WORDS Phenolic Resin / Polymer Hybrid / Novolac / Silica / Aromatic Interaction / Heat-Resistant Material / [doi:10.1295/polymj.PJ2005224]
\end{abstract}

Recently, much attention has focused on the preparation of nano-ordered hybrid material consisting of both organic and inorganic moieties (metal oxide such as silica, titania, and alumina) using the sol-gel technique. ${ }^{1-14}$ Especially, the preparation of a polymer hybrid by utilizing physical interactions such as hydrogen bonding, ${ }^{1}$ aromatic ${ }^{13}$ and ionic ${ }^{14}$ interactions is convenient method. These materials showed significant properties such as a high thermal stability, filmforming property, and good mechanical property due to the nano-ordered combination. They are also expected to reveal several significant functions from each starting material.

Tamaki previously reported a preparation of the polystyrene-silica gel polymer hybrid from an arylalkoxysilane utilizing the aromatic $\pi-\pi$ interaction. ${ }^{13}$ This method is a strong process for the formation of nano-ordered hybrid materials from a hydrophobic aromatic polymer. However, little is known about these examples. It is very important to extend this scope toward other aromatic polymers such as engineering plastics or thermosetting resins.

In this paper, we report the preparation of organic/ inorganic polymer hybrids from a new class of novolac (phenolic resin) derivatives utilizing the aromatic $\pi-\pi$ interaction. (Figure 1) Previously, the preparation of the phenolic resin-silica gel polymer hybrids by the sol-gel reaction using the low molecular weight resole $^{15}$ (phenolic resin having phenolic hydroxyl and hydroxymethyl groups) and alkoxysilane were reported. However, these polymer hybrids might be utilized by the hydrogen bond interaction and the covalent bond formation. It is necessary to develop a more general preparation method for future applications of novolac derivatives. ${ }^{16,17}$ The nano-orderd silica-novolac composite is expected to exhibit good

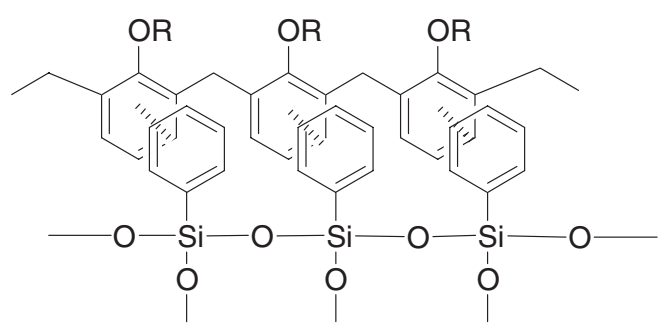

Figure 1. $\pi-\pi$ Interaction between polymer and silica matrix.
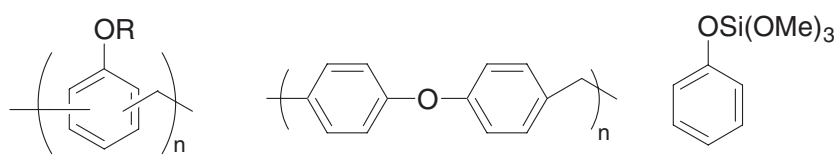

$1(R=M e) ; 2(R=E t)$

3

PhTMOS

thermal stability, mechanical properties, processability of coating and so on.

The new class of novolac derivatives, i.e., the precursors of the polymer hybrids, are listed in Figure 2. ${ }^{18-20}$ These are alkoxylated novolacs which are well-soluble in poor solvents for phenol novolac such as chloroform and toluene, and are more stable to heat, acid, and oxidation than that of the common novolac due to the effect of protecting of the phenolic hydroxyl group. Therefore, these are unique aromatic polymer materials.

Anisole novoalc $(\mathbf{1})^{18} \quad\left(M_{\mathrm{n}}=2500, \quad M_{\mathrm{w}} / M_{\mathrm{n}}=\right.$ $1.16),{ }^{21}$ phenetole novolac $(2)^{18}\left(M_{\mathrm{n}}=3000, M_{\mathrm{w}} /\right.$ $\left.M_{\mathrm{n}}=1.12\right)$, and diphenyl ether novolac $(\mathbf{3})^{19}\left(M_{\mathrm{n}}=\right.$ $2900, M_{\mathrm{w}} / M_{\mathrm{n}}=1.11$ ) were prepared by the sulfuric acid-catalyzed addition-condensation of the corresponding monomers with formaldehyde (paraformaldehyde).

\footnotetext{
${ }^{\dagger}$ To whom correspondence should be addressed (Tel: +81-3-5734-2321, Fax: +81-3-5734-2888, E-mail: gkonishi@polymer.titech.ac.jp).

${ }^{\dagger \dagger}$ Present address: Tokyo Institute of Technology, Ookayama, Meguro-ku, Tokyo 152-8552, Japan
} 


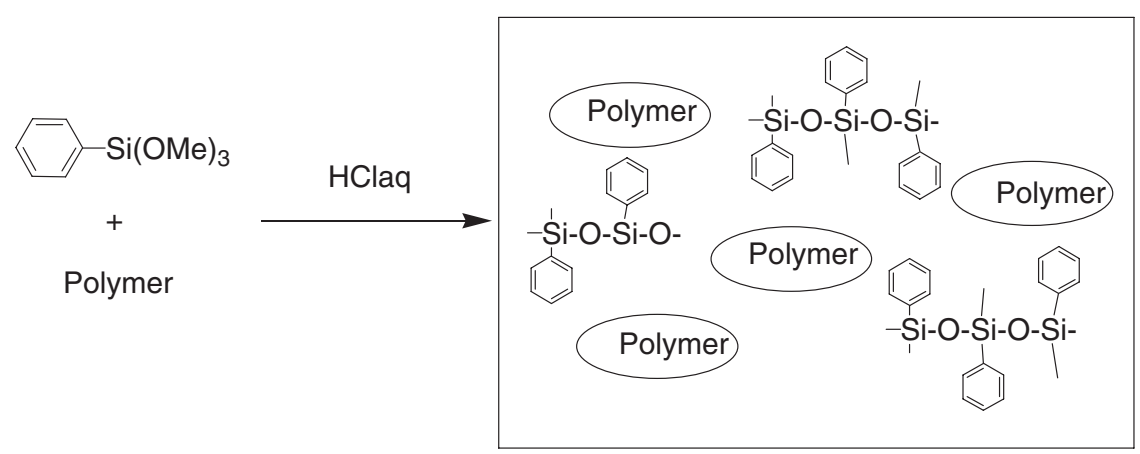

Polymer Hybrid

Scheme 1. Preparation of polymer hybrid.

The organic/inorganic polymer hybrid was prepared by the hydrochloric acid $(\mathrm{HCl})$-catalyzed solgel reaction of phenyltrimethoxysilane (PhTMOS) in the presence of anisole novolac (1). (Scheme 1) The typical procedure is as follows (run 8). PhTMOS $(500 \mathrm{mg})$ and anisole novolac $(500 \mathrm{mg})$ were dissolved into THF $(15 \mathrm{~mL})$, and aqueous $\mathrm{HCl}(1 \mathrm{~mL}, 0.1 \mathrm{~mol} /$ L) was added as a catalyst for the sol-gel reaction in room temperature. The mixture was stirred for 30 min in a glass bottle and then irradiated with weak supersonic waves for $10 \mathrm{~min}$. The resulting mixture was then placed in a clear polypropylene (PP) container covered with a paper towel, and left in the drying apparatus. The temperature was raised to $80^{\circ} \mathrm{C}$ at the rate of $10^{\circ} \mathrm{C} / 10 \mathrm{~min}$ (reaction rate: "Fast condition") and then kept at the same temperature for four days. After the drying solvents were completely removed in vacuo, a transparent PhTMOS film containing anisole novolac was then obtained, which is a colourless and hard glassy material. The homogeneity of the obtained polymer hybrids was evaluated by optical observations. This makes possible to prepare a hybrid glass having a high content of the novolac derivatives.

On the other hand, for the "Slow condition" (heating rate of $10^{\circ} \mathrm{C} / 1 \mathrm{~h}$ ), a phase separation occurred. The transparent polymer hybrid could not be obtained regardless of polymer content (run 2, 4, 6, 10, 12, 14).

Similar reactions in the presence of phenetole novolac (2) afforded the corresponding polymer hybrids. However, no polymer hybrid was obtained from the diphenyl ether novolac $(3)$ because of its poor solubility at a high concentration.

It is noted that the most significant factor for the successful synthesis of the polymer hybrid was the "heating rate." This evidence suggests that it is necessary for obtaining a transparent polymer hybrid to form the silica matrix (sol) before the polymer aggregates. In general, novolac has a spherical structure in dilute solution and does not have a film-forming property. ${ }^{16}$ This required condition may relate to the char-
Table I. Preparation and homogeneity of polymer hybrids

\begin{tabular}{|c|c|c|c|c|}
\hline Run & Polymer & $\begin{array}{l}\text { Polymer: } \\
\text { PhTMOS }\end{array}$ & $\begin{array}{c}\text { Reaction } \\
\text { Rate }\end{array}$ & Appearance \\
\hline 1 & \multirow{8}{*}{$\begin{array}{l}\text { Anisole } \\
\text { Novolac }\end{array}$} & \multirow{2}{*}{$1: 10$} & Fast & Transparent \\
\hline 2 & & & Slow & Turbid \\
\hline 3 & & \multirow{2}{*}{$1: 5$} & Fast & Transparent \\
\hline 4 & & & Slow & Turbid \\
\hline 5 & & \multirow{2}{*}{$1: 2$} & Fast & Transparent \\
\hline 6 & & & Slow & Turbid \\
\hline 7 & & $4: 5$ & Fast & Transparent \\
\hline 8 & & $1: 1$ & Fast & Transparent \\
\hline 9 & \multirow{8}{*}{$\begin{array}{l}\text { Phenetole } \\
\text { Novolac }\end{array}$} & \multirow{2}{*}{$1: 10$} & Fast & Transparent \\
\hline 10 & & & Slow & Turbid \\
\hline 11 & & \multirow{2}{*}{$1: 5$} & Fast & Transparent \\
\hline 12 & & & Slow & Turbid \\
\hline 13 & & \multirow{2}{*}{$1: 2$} & Fast & Transparent \\
\hline 14 & & & Slow & Turbid \\
\hline 15 & & $4: 5$ & Fast & Transparent \\
\hline 16 & & $1: 1$ & Fast & Transparent \\
\hline 17 & \multirow{3}{*}{$\begin{array}{l}\text { Diphenyl Ether } \\
\text { Novolac }\end{array}$} & \multirow{2}{*}{$1: 10$} & Fast & Turbid \\
\hline 18 & & & Slow & Turbid \\
\hline 19 & & $1: 5$ & Fast & Turbid \\
\hline
\end{tabular}

${ }^{\mathrm{a}}$ Based on the weights.

acteristic of the novolac.

The results are summarized in Table I.

Figure 3 shows a scanning electron microscope (SEM) images of the polymer hybrid (Run 8) and turbid sample (Run 6). ${ }^{22}$ As expected, no nano-scale phase separation was confirmed in this sample.

The driving force of the dispersion of the two components might be the $\pi-\pi$ interaction between the phenyl ring of the silica matrix and that of novolac. The evidence for the interaction was not supported by the spectroscopic measurements such as NMR, UV, and FT-IR. Although it is indirect evidence, a transparent anisole-silica hybrid was not obtained using tetramethoxysilane (TMOS) and tetraethoxysilane (TEOS) instead of PhTMOS. Therefore, the aromatic 
interaction plays a critical role in the homogeneous integration of the polymer and silica matrix. ${ }^{13}$ There

(a)

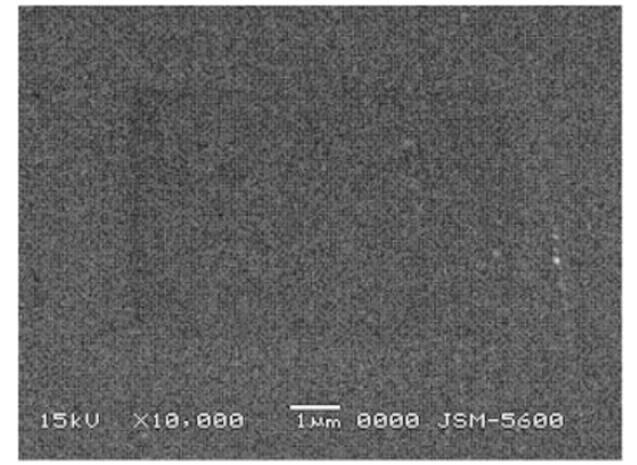

(b)

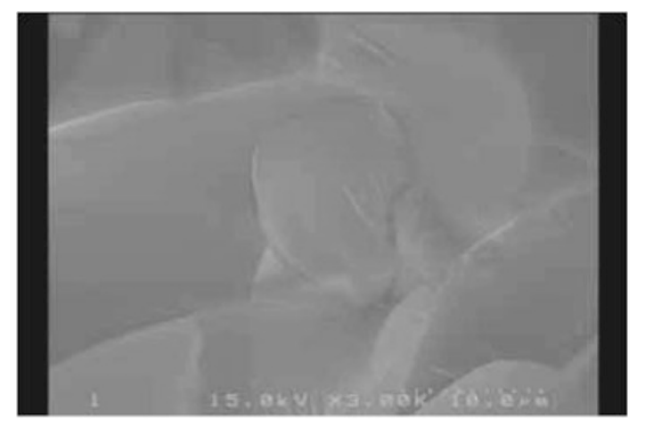

Figure 3. SEM images of polymer hybrid (Run 8) (a) and turbid sample (Run 6) (b) (ref. 22). is no other effective interaction.

Figure 4 shows the thermogravimetric analysis (TGA) of the polymer hybrid (Run 8$)^{23}$ and its anisole novolac (precursor) (1). In the case of nitrogen atmosphere condition (Figure 4(a)), the $10 \%$ weight loss of the polymer hybrid was $420^{\circ} \mathrm{C}$ and the weight loss of polymer hybrid at $700{ }^{\circ} \mathrm{C}$ was $40 \%$. The residue might be mainly carbon and silica. On the other hand, in the case of air condition (Figure 4(b)), the 10\% weight loss of the polymer hybrid was $400{ }^{\circ} \mathrm{C}$ and the weight loss at $800^{\circ} \mathrm{C}$ was $75 \%$. The residue might be mainly silica $\left(\mathrm{SiO}_{2}\right)$. This polymer hybrid has a significant potential as a heat-resistant material.

In conclusion, functional novolac-silica gel polymer hybrids were prepared by the sol-gel reaction of phenyltrimethoxysilane (PhTMOS). The obtained polymer hybrid was a high heat-resistant and hydrophobic material which will be applicable for coatings, plastic lens, etc. A new material science of a novolac film or composite will be developed by this methodology.

We thank Dr. T. Ogoshi (Kyoto University) and Dr. T. Kawamura (Kanazawa University) for the SEM measurements. This work was partially supported by the Industrial Technology Research and Development Project (No. 04A23030) from NEDO of Japan and the Asahi Glass Foundation for Young Scientist.
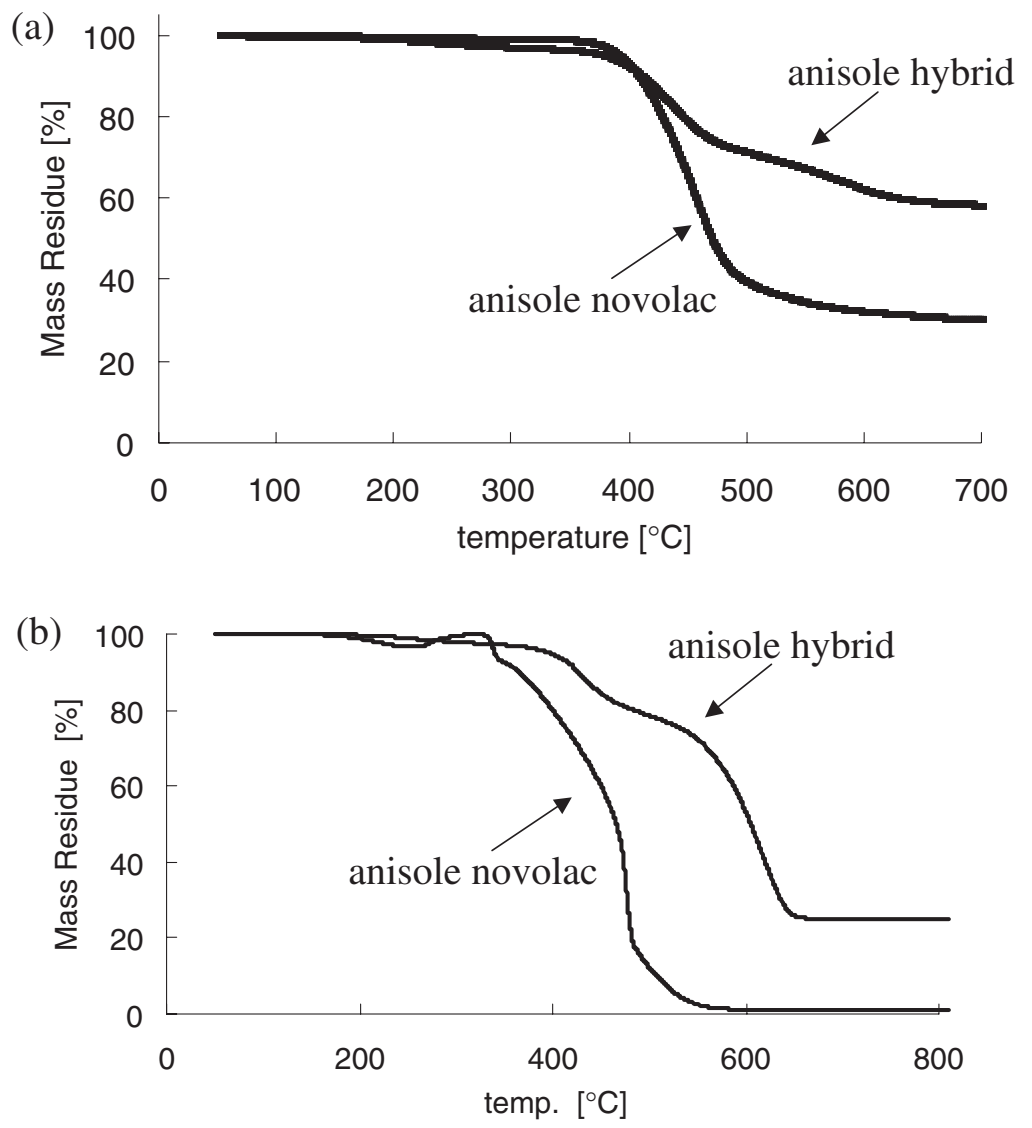

Figure 4. TGA thermograms of anisole novolac and hybrid (Run 8); a: under air; b: under nitrogen (ref. 23). 


\section{REFERENCES AND NOTES}

1. Y. Chujo and T. Saegusa, Adv. Polym. Sci., 100, 11 (1992).

2. B. M. Novak, Adv. Mater., 5, 422 (1993).

3. C. M. Brick, Y. Ouchi, Y. Chujo, and R. M. Laine, Macromolecules, 38, 4661 (2005).

4. T. Iwamura, K. Adachi, and Y. Chujo, Polym. J., 36, 871 (2004).

5. T. Ogoshi, Y. Chujo, and A. Esaki, Polym. J., 37, 686 (2005).

6. T. Sanji, Y. Nakatsuka, and H. Sakurai, Polym. J., 37, 1 (2005).

7. S. Satoh, B. Fugetsu, M. Nomizu, and N. Nishi, Polym. J., 37, 94 (2005).

8. K. Matsukawa, J. Photopolym. Sci. Technol., 18, 203 (2005).

9. T. Gunji, M. Yokogawa, M. Hongo, and Y. Abe, J. Polym. Sci., Part A: Polym. Chem., 43, 763 (2005).

10. T. Gunji, Y. Kawaguchi, H. Okonogi, T. Sakan, K. Arimitsu, and Y. Abe, J. Sol-Gel Sci. Technol., 33, 9 (2004).

11. K. Adachi, T. Iwamura, and Y. Chujo, Chem. Lett., 33, 1504 (2004).
12. T. Nakamura, M. Takeuchi, H. Yamashita, and M. Anpo, Chem. Lett., 35, 106 (2006).

13. R. Tamaki, K. Samura, and Y. Chujo, Chem. Commun., 1131 (1998).

14. R. Tamaki and Y. Chujo, Chem. Mater., 11, 1719 (1999).

15. K. Haraguchi, Y. Usami, and Y. Ono, J. Mater. Sci., 33, 3337 (1998).

16. G. Konishi, T. Kimura, T. Yamagishi, and Y. Nakamoto, J. Network Polym. Jpn., 25, 200 (2004).

17. A. Igarashi, T. Terasawa, M. Kanie, T. Yamanobe, and T. Komoto, Polym. J., 37, 522 (2005).

18. G. Konishi et al. Manuscript in preparation.

19. A. Ninagawa, I. Ijichi, and M. Imoto, Makromol. Chem., 107, 196 (1967).

20. Dipenyl Ether Novolac Polymer: G. Konishi et al. Manuscript in preparation.

21. GPC analyses were carried out Shodex TSKgelG3000HXL column using THF as a eluent (polystyrene standard).

22. SEM measurement was conducted with a JEOL JSM-5600 at $15 \mathrm{kV}$.

23. TGA analysis was performed on a SII TGA/DTA 6200 with a heating rate of $10^{\circ} \mathrm{C} / \mathrm{min}$ under nitrogen atmosphere or air. 